\title{
The Effect of New Rural Cooperative Medical Scheme on the Socioeconomic Inequality in Inpatient Service Utilization Among the Elderly in China
}

This article was published in the following Dove Press journal: Risk Management and Healthcare Policy

\author{
Jian Sun' \\ Xiaoyin Lyu (D) ${ }^{2}$ \\ Fan Yang (D) ${ }^{1,3}$
}

'School of International and Public Affairs, Shanghai Jiao Tong University, Shanghai 200030, People's Republic of China; ${ }^{2}$ High School Affiliated to Shanghai Jiao Tong University, Shanghai 200439, People's Republic of China; ${ }^{3}$ China Institute for Urban Governance, Shanghai Jiao Tong University, Shanghai 200030, People's Republic of China
Correspondence: Fan Yang

School of International and Public Affairs, Shanghai Jiao Tong University, Shanghai 200030, People's Republic of China

Tel +86-137-7430-5290

Email fan_yang86@sjtu.edu.cn
Background and Aim: Health equity is an important goal of health policy, and the equalization of access to health care plays a vital role in guaranteeing it. The aim of this study was to use the cross-sectional data to explore the effect of New Rural Cooperative Medical Scheme (NRCMS) on the socioeconomic inequality in inpatient service utilization among the elderly in china.

Methods: The data of this study were obtained from the 2018 wave of China Family Panel Studies (CFPS), involving 3645 older adults aged 60 and above. Furthermore, concentration index and concentration curve were employed to measure the socioeconomic inequality in inpatient service utilization. Moreover, this study used multiple linear regression model to explore the effect of NRCMS on inpatient service utilization. In addition, this study adopted the decomposition of concentration index to investigate the effect of NRCMS on the socioeconomic inequality of inpatient service utilization.

Results: The concentration index of inpatient expense for the older people was 0.0538 , and its concentration curve lays below the diagonal. The regression result indicates that NRCMS was significantly associated with higher inpatient expense among the elderly (coefficient = $0.8749, p<0.01$ ). The decomposition result reveals that the contribution rate of NRCMS to concentration index was $-2.29 \%$, which indicates that its contribution on reducing pro-rich inequality in inpatient service utilization was limited.

Conclusion: This study demonstrates that there was a pro-rich inequality in inpatient service utilization among the elderly. Furthermore, NRCMS was significantly associated with higher inpatient expense. Moreover, NRCMS only played a limited role in reducing prorich inequality in inpatient service utilization.

Keywords: socioeconomic inequality, inpatient service utilization, elderly, New Rural Cooperative Medical Scheme, China

\section{Introduction}

Health equity is an important goal of health policy, and the equalization of access to health care plays a vital role in guaranteeing it. There exist huge socioeconomic gaps between urban and rural China. ${ }^{1}$ Given that per capita income of urban households was three times of that of rural households in $2015,^{2}$ the inequality status in health service utilization is more serious there. Furthermore, older adults in China suffer from serious physical and mental health problems. ${ }^{3-5}$ Though China's economy has continued to grow during the recent decades, a large proportion of the rural population did not have access to health service when needed due to financial 
barriers. $^{6,7}$ To address this problem, New Rural Cooperative Medical Scheme (NRCMS) was established by the Chinese government in 2003, targeting rural residents with subsidies from central and local governments. ${ }^{8}$ In addition, NRCMS is a voluntary scheme, and rural residents take part in it by taking the family as the unit.

The purpose of NRCMS is to prevent households from experiencing catastrophic health expenditure (CHE), improve the utilization of health service, and reduce the socioeconomic inequality in health service utilization. ${ }^{9}$ The annual premium per capita has gradually increased from RMB 40 (US\$ 4.88) in 2005 to RMB 400 (US\$ 65.11 ) in $2014 .{ }^{10}$ By the end of 2018, 130.38 million rural residents were covered by NRCMS. In terms of reimbursement policy, NRCMS provides financial protection by bearing a proportion of health expenditures. Moreover, the reimbursement coverage of NRCMS mainly involved serious diseases, and it has a higher reimbursement rate on inpatient service than outpatient service. However, the effect of NRCMS expansion has been offset by the rapid escalation of health expenditures. ${ }^{11}$ Furthermore, a study also revealed that NRCMS has not reduced participants' out-of-pocket spending. ${ }^{12}$

Previous studies have explored the effect of health insurance on the socioeconomic inequality in health service utilization. Chen et al found that the effect of NRCMS on promoting equity in health services has not been significant. ${ }^{13}$ In contrast, the study of Feng and Liu suggests that NRCMS has a positive contribution in increasing the pro-poor inequality in health-care utilization. ${ }^{14}$ Furthermore, a study which is conducted by Zhou et al reveals that health insurance has effectively reduced the income-related inequality in inpatient service utilization for the residents in China. ${ }^{15}$ In addition, Zhou et al discovered that Urban Employee Basic Medical Insurance (UEBMI) scheme increased the pro-rich inequity of outpatient utilisation and Urban Resident Basic Medical Insurance (URBMI) scheme increased the pro-poor inequity of outpatient utilisation. ${ }^{16}$

In summary, we observed that fewer empirical studies have explored the impact of NRCMS on the socioeconomic inequality in inpatient service utilization for the elderly. To fulfill this gap, this study aims to explore the effect of NRCMS on the socioeconomic inequality in inpatient service utilization among the elderly in China, using the 2018 wave of China Family Panel Studies data. The results of this study could shed light on future studies concerning the effect of NRCMS on socioeconomic inequality in inpatient service utilization.

\section{Methods \\ Data Source}

The data of this study were obtained from the 2018 wave of China Family Panel Studies (CFPS). CFPS data are freely available at http://www.isss.pku.edu.cn/cfps/. CFPS is a nationally representative longitudinal survey of households in China. Furthermore, CFPS is conducted by Institute of Social Science Survey (ISSS) of Peking University, which provides high-quality micro-data for both public policy analysis and academic research. Moreover, CFPS sampled approximately 57,000 individuals from 15,000 households in 25 provinces of China by using a multistage probability-proportional-to-size (PPS) sampling technique. In addition, the first wave of CFPS was conducted in 2008, and the 2018 wave of CFPS is the latest wave of data available at the time of this study. The data in the CFPS are not de-identified. This data is ideal for this study because it collects rich information concerning inpatient service utilization, health insurance, social demographic characteristics, income, health status, and so on. After removing cases with missing information, 3645 older adults aged 60 and above were included in this study.

\section{Variables Dependent Variable}

Given the fact that inpatient expense can comprehensively reflect inpatient service utilization, this study used it to measure inpatient service utilization. If inpatient expense is zero, we will add 1 to it and then take the logarithm. If inpatient expense is more than zero, we will take the logarithm directly.

\section{Independent Variable}

Given that this study focused on the effect of NRCMS on socioeconomic inequality in inpatient service utilization among the elderly, the independent variable is NRCMS, which is a dummy variable, indicating whether or not the older adult is covered by NRCMS.

\section{Control Variables}

Considering the fact that Anderson health service utilization model is a well-validated theoretical framework and has been widely used to investigate the influencing factors of health service utilization (including outpatient service 
utilization, inpatient service utilization, etc.), ${ }^{17-19}$ this study employed it to determine control variables. Taking into account both societal and individual determinants via systematic analysis, ${ }^{20}$ Anderson health service utilization model indicates that predisposing factors, enabling factors, and need factors significantly influence the utilization of health service. ${ }^{21}$ Predisposing factors are social demographic characteristics of the individual that exist prior to their health condition, which can increase their need for health service, such as age, race, gender, marital status, and educational level. In addition, enabling factors facilitate health service utilization, such as the access to health insurance and income. Furthermore, need factors are the most immediate cause of health service utilization and can reflect the actual need for health service, ${ }^{22}$ such as health status.

In this study, the predisposing factors include age, gender, marital status, and educational level. Furthermore, the enabling factor includes household income per capita. Moreover, the need factors include selfassessed health and chronic disease.

In addition, this study conducted a Variance Inflation Factor (VIF) test to test whether there exists serious multicollinearity in this study. The test shows that the mean VIF value is 1.26 , and the VIF values of independent variable and control variables are far lower than the critical value of 10 , indicating that there is no serious multicollinearity across the regression model.

\section{Statistical Analyses}

Since concentration index and concentration curve are useful tools used for assessing the degree of socioeconomic inequality in health service utilization, this study employed them to measure the socioeconomic inequality in inpatient service utilization. The concentration index is defined as twice the area between the concentration curve and the diagonal. The concentration index ranges from -1 to $+1 .^{23-26}$ The concentration curve plots the cumulative proportion of inpatient service utilization on the $y$-axis against the cumulative proportion of the sample on the x-axis, ranked by household income per capita from the poorest to the richest. ${ }^{27}$ When the concentration index takes a positive value, the concentration curve lies below the diagonal, which indicates that inpatient service utilization is more concentrated among the higherincome older people, and vice versa. ${ }^{28-30}$ When the concentration index takes the value of zero, the concentration curve coincides with the diagonal, which indicates that there is no socioeconomic inequality in inpatient service utilization. ${ }^{31,32}$ Furthermore, when the concentration curve farther lies above (or below) the diagonal, the absolute value of concentration index is larger, which indicates a greater degree of socioeconomic inequality in inpatient service utilization. ${ }^{33}$ The formula used for calculating concentration index is as follows:

$$
\mathrm{C}=\frac{2}{\mu} \operatorname{COV}(y, \gamma)
$$

where $\mathrm{C}$ indicates the concentration index, $\mu$ denotes the mean of inpatient service utilization indicator, $y$ represents the inpatient service utilization indicator, and $r$ is the fractional rank of household income per capita.

Given the fact that inpatient expense is a continuous variable, this study used multiple linear regression model to explore the effect of NRCMS on inpatient service utilization. The multiple linear regression model is as follows:

$$
\operatorname{lnIE}=\beta_{0}+\beta_{1} * N R C M S_{i}+\beta_{2} * C V_{i}+\varepsilon_{i}
$$

where $\mathrm{i}$ denotes the individual, IE indicates the inpatient expense, $\mathrm{CV}_{\mathrm{i}}$ stands for the control variables, $\varepsilon_{\mathrm{i}}$ is the error term. $\beta_{0}$ refers to the intercept term, $\beta_{1}$ and $\beta_{2}$ are the regression coefficients for NRCMS and control variables, respectively.

Considering the fact that decomposition of concentration index can present the contribution of each variable to the concentration index, this study adopted it to investigate the effect of NRCMS on the socioeconomic inequality of inpatient service utilization. The formula used for the decomposition of concentration index is as follows:

$$
c=\sum_{k}(\beta \mathrm{k} \overline{\mathrm{xk}} / \mu) C k+G C_{\varepsilon} / \mu
$$

where $\mathrm{C}$ is the concentration index, $\beta_{\mathrm{k}}$ is the coefficient of $\mathrm{x}_{\mathrm{k}}$, $\mathrm{x}_{\mathrm{k}}$ represents the mean of $\mathrm{x}_{\mathrm{k}}, \mu$ stands for the mean of inpatient service utilization, $\mathrm{C}_{\mathrm{k}}$ is the concentration index for $\mathrm{x}_{\mathrm{k}}$, and GC denotes the generalized concentration index for $\varepsilon_{\mathrm{i}}$.

In this study, STATA SE 15.1 was employed to conduct descriptive statistics, calculate concentration index, draw concentration curve, construct multiple linear regression model, and perform the decomposition of concentration index. All tests were two-sided and a $p$-value $<0.05$ indicates statistical significance.

\section{Ethical Considerations}

The study received ethical approval from the Ethics Committee of Shanghai Jiao Tong University. 


\section{Results}

\section{Characteristics of the Study Population}

Table 1 reports the characteristics of the study population. Most respondents aged less than 70 , and $50.15 \%$ of them were men. In addition, more than $80 \%$ of the respondents were married, and more than half of them were illiterate. Furthermore, the mean of household income per capita was RMB 12,249.40 (US\$ 1,751.67), and over $92 \%$ of them were covered by NRCMS. Moreover, approximately $50 \%$ of the respondents were healthy, and more than $30 \%$ of them had chronic diseases.

\section{Socioeconomic Inequality in Inpatient Service Utilization}

The concentration index of inpatient expense for the older people was 0.0538 , indicating that higher-income older people utilized more inpatient services, favoring the rich. Figure 1 displays the concentration curve of inpatient expense. The concentration curve of inpatient expense

Table I Characteristics of the Study Population

\begin{tabular}{|c|c|}
\hline Variables & All $(N=3645)$ \\
\hline \multicolumn{2}{|l|}{ Age } \\
\hline $60-69, \mathrm{n}(\%)$ & $2440(66.94)$ \\
\hline 70-79, n (\%) & $1037(28.45)$ \\
\hline$\geq 80, \mathrm{n}(\%)$ & $168(4.6 \mathrm{I})$ \\
\hline \multicolumn{2}{|l|}{ Gender } \\
\hline Women, n (\%) & $1817(49.85)$ \\
\hline Men, n (\%) & $1828(50.15)$ \\
\hline \multicolumn{2}{|l|}{ Marital status } \\
\hline Single, divorced or widowed, $\mathrm{n}(\%)$ & $718(19.70)$ \\
\hline Married, n (\%) & $2927(80.30)$ \\
\hline \multicolumn{2}{|l|}{ Educational level } \\
\hline Illiterate, n (\%) & $2098(57.56)$ \\
\hline Primary school, n (\%) & $874(23.98)$ \\
\hline Secondary school and above, $\mathrm{n}(\%)$ & $673(18.46)$ \\
\hline \multicolumn{2}{|l|}{ Household income per capita (RMB) } \\
\hline Mean (SD) & $12,249.40(20,357.19)$ \\
\hline \multicolumn{2}{|l|}{ NRCMS } \\
\hline Without NRCMS, n (\%) & $261(7.16)$ \\
\hline Covered by NRCMS, n (\%) & $3384(92.84)$ \\
\hline \multicolumn{2}{|l|}{ Self-assessed health } \\
\hline Healthy, n (\%) & $|83|(50.23)$ \\
\hline Unhealthy, n (\%) & $1814(49.77)$ \\
\hline \multicolumn{2}{|l|}{ Chronic diseases } \\
\hline Have no chronic disease, $\mathrm{n}(\%)$ & 2533 (69.49) \\
\hline Have chronic diseases, n (\%) & $1112(30.51)$ \\
\hline
\end{tabular}

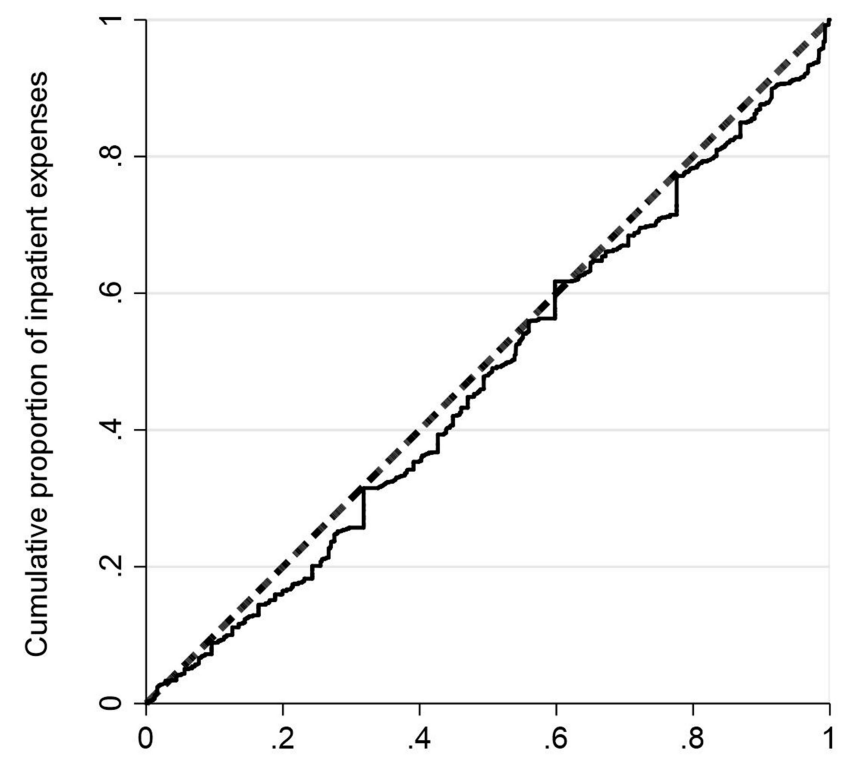

Rank of household income per capita

Figure I Concentration curve of inpatient expense.

lay below the diagonal, which also indicates that higherincome older people utilized more inpatient services. This result is consistent with the value of concentration index.

\section{The Effect of NRCMS on Inpatient}

\section{Service Utilization}

Table 2 provides the regression results of the effect of NRCMS on inpatient service utilization. The Model 1 indicates that NRCMS was significantly associated with higher inpatient expense among the elderly (coefficient $=0.8749$, $p<0.01$ ). Specifically speaking, this means that participation in NRCMS was significantly associated with a $139.86 \%$ increase in inpatient expense after adjusting for the control variables. In addition, it was also found that being older $(p<$ 0.05 ), unhealthy (coefficient $=1.2659, p<0.01$ ), having chronic diseases (coefficient $=1.7048, p<0.01$ ) were significantly related to more inpatient expenses. Furthermore, we also obtained evidence indicating that gender (coefficient $=0.1015, p>0.05$ ), marital status (coefficient $=-0.0795, p>$ $0.05)$, and educational level $(p>0.05)$ were not significantly related to inpatient expense. Moreover, we discovered that household income per capita was not significantly associated with inpatient expense (coefficient $=-0.0118, p>0.05$ ). The reason may lie in the fact that higher-income older adults have more health knowledge and better health outcome.

Based on Model 1, we added the interaction term between NRCMS and household income per capita to explore the moderating effect. The regression results 
Table 2 Regression Results of the Effect of NRCMS on Inpatient Service Utilization

\begin{tabular}{|c|c|c|}
\hline Variables & Model I & Model 2 \\
\hline $\begin{array}{l}\text { NRCMS } \\
\text { Without NRCMS } \\
\text { Covered by NRCMS }\end{array}$ & $\begin{array}{l}\text { Ref. } \\
0.8749 * *(0.2239)\end{array}$ & $\begin{array}{l}\text { Ref. } \\
2.5277(-1.7181)\end{array}$ \\
\hline $\begin{array}{l}\text { Age } \\
\begin{array}{l}60-69 \\
70-79 \\
\geq 80\end{array}\end{array}$ & $\begin{array}{l}\text { Ref. } \\
0.4618 * *(0.1329) \\
0.6421 *(0.2878)\end{array}$ & $\begin{array}{l}\text { Ref. } \\
0.4580 *(-0.1329) \\
0.6289 *(-0.2882)\end{array}$ \\
\hline $\begin{array}{l}\text { Gender } \\
\text { Women } \\
\text { Men }\end{array}$ & $\begin{array}{l}\text { Ref. } \\
0.1015(0.1250)\end{array}$ & $\begin{array}{l}\text { Ref. } \\
0.0997(-0.1250)\end{array}$ \\
\hline $\begin{array}{l}\text { Marital status } \\
\text { Single, divorced or } \\
\text { widowed } \\
\text { Married }\end{array}$ & $\begin{array}{l}\text { Ref. } \\
-0.0795(0.1528)\end{array}$ & $\begin{array}{l}\text { Ref. } \\
-0.0818(-0.1528)\end{array}$ \\
\hline $\begin{array}{l}\text { Educational level } \\
\text { Illiterate } \\
\text { Primary school } \\
\text { Secondary school and } \\
\text { above } \\
\text { Household income per } \\
\text { capita }\end{array}$ & $\begin{array}{l}\text { Ref. } \\
0.2316(0.1656) \\
0.3196(0.1800) \\
-0.0118(0.0590)\end{array}$ & $\begin{array}{l}\text { Ref. } \\
0.2334(-0.1656) \\
0.3186(-0.1800) \\
0.1556(-0.1824)\end{array}$ \\
\hline $\begin{array}{l}\text { Self-assessed health } \\
\text { Healthy } \\
\text { Unhealthy }\end{array}$ & $\begin{array}{l}\text { Ref. } \\
1.2659 * *(0.1192)\end{array}$ & $\begin{array}{l}\text { Ref. } \\
1.2669 * *(-0.1192)\end{array}$ \\
\hline $\begin{array}{l}\text { Chronic diseases } \\
\text { Have no chronic disease } \\
\text { Have chronic diseases } \\
\text { NRCMS * Household } \\
\text { income per capita } \\
\text { Constant }\end{array}$ & $\begin{array}{l}\text { Ref. } \\
\text { I.7048** }(0.1285)\end{array}$ & $\begin{array}{l}\text { Ref. } \\
\text { I.7016** (-0.1286) } \\
-0.1865(-0.1923) \\
-1.7505(-1.6487)\end{array}$ \\
\hline
\end{tabular}

Notes: Ref. indicates the reference group. Standard errors are given in parentheses. ${ }^{*} p<<0.01,{ }^{*} p<0.05$.

were displayed in Model 2, which reveals that the interaction term was not statistically significant (coefficient $=$ $-0.1865, p>0.05)$, indicating that household income per capita did not moderate the association between NRCMS and inpatient expense.

\section{The Effect of NRCMS on Socioeconomic Inequality in Inpatient Service Utilization}

Table 3 shows the decomposition results of the effect on NRCMS on socioeconomic inequality in inpatient service utilization. The concentration index value of NRCMS was positive, which indicates that higher-income older people are more likely to be covered by it. In contrast, the concentration index values of being illiterate, unhealthy, and having chronic diseases were negative, which reveals that lower-income older adults were more likely to be illiterate, unhealthy, and have chronic diseases.

The decomposition result reveals that the contribution rate of NRCMS to concentration index was $-2.29 \%$, which indicates that its contribution on reducing pro-rich inequality in inpatient service utilization was limited. Furthermore, the decomposition result also indicates that being unhealthy (40.81\%) made the biggest contribution to the pro-rich inequality in inpatient service utilization. Moreover, we also observed that ageing 70-79 (17.07\%) made a major contribution to the socioeconomic inequality in inpatient service utilization. Except the above, other factors, such as having chronic diseases (16.66\%), being illiterate $(8.97 \%)$, household income per capita $(7.99 \%)$, and aging 80 and above $(4.50 \%)$ were also observed to make contributions to the pro-rich inequality in inpatient service utilization.

\section{Discussion}

Using the national representative data from the CFPS that was conducted in 2018, this study explored the effect of NRCMS on socioeconomic inequality in inpatient service utilization among the elderly in China. We observed that there is a pro-rich socioeconomic inequality in inpatient service utilization, which implies that higher-income older adults utilized more inpatient services. The reason may lie in the fact that higher-income older people have higher requirement for health outcome and more fund to buy more higher-quality inpatient services regardless of the health insurance system. ${ }^{34}$ This finding is consistent with the finding of Zhou et al ${ }^{15}$ who used the data obtained from Chinese National Health Services Surveys (NHSS) and found that there remains a strong pro-rich inequity of inpatient utilization in rural China. However, this finding is not consistent with the finding of Wang et $\mathrm{al}^{35}$ who employed the 2015 wave of China Health and Retirement Longitudinal Study (CHARLS) data and discovered that there is a pro-poor inequity in inpatient service utilization.

We also obtained evidence indicating that NRCMS was positively associated with inpatient expense among the Chinese older adults. This finding is similar to previous studies, ${ }^{36-40}$ and they all found that health insurance increased the inpatient service utilization. However, this finding is different from the finding of Zhang et $\mathrm{al}^{41}$ who 
Table 3 Decomposition Results of the Effect of NRCMS on Socioeconomic Inequality in Inpatient Service Utilization

\begin{tabular}{|c|c|c|c|c|}
\hline Variables & Elasticity & $C_{k}$ & Absolute Contribution to C & Percentage Contribution to $\mathrm{C}$ \\
\hline \multicolumn{5}{|l|}{ NRCMS } \\
\hline Without NRCMS & Ref. & & & \\
\hline Covered by NRCMS & 0.4181 & 0.0023 & 0.0009 & -2.29 \\
\hline \multicolumn{5}{|l|}{ Age } \\
\hline $60-69$ & Ref. & & & \\
\hline $70-79$ & 0.0676 & -0.1045 & $-0.007 \mid$ & 17.07 \\
\hline$\geq 80$ & 0.0152 & -0.1223 & -0.0019 & 4.50 \\
\hline \multicolumn{5}{|l|}{ Gender } \\
\hline Women & Ref. & & & \\
\hline Men & 0.0262 & -0.0009 & $-2.3 \mathrm{E}-05$ & 0.06 \\
\hline \multicolumn{5}{|l|}{ Marital status } \\
\hline Single, divorced or widowed & Ref. & & & \\
\hline Married & -0.0329 & 0.0049 & -0.0002 & 0.39 \\
\hline \multicolumn{5}{|l|}{ Educational level } \\
\hline Illiterate & 0.0686 & -0.0542 & -0.0037 & 8.97 \\
\hline Primary school & 0.0394 & 0.0523 & 0.0021 & -4.98 \\
\hline Secondary school and above & Ref. & & & \\
\hline Household income per capita & -0.0542 & 0.0611 & -0.0033 & 7.99 \\
\hline \multicolumn{5}{|l|}{ Self-assessed health } \\
\hline Healthy & Ref. & & & \\
\hline Unhealthy & 0.3243 & -0.0521 & -0.0169 & 40.81 \\
\hline \multicolumn{5}{|l|}{ Chronic diseases } \\
\hline Have no chronic disease & Ref. & & & \\
\hline Have chronic diseases & 0.2677 & -0.0258 & -0.0069 & 16.66 \\
\hline
\end{tabular}

Notes: Elasticity refers to the degree the concentration index values of independent variables affect the concentration index of dependent variable; $C_{k}$ denotes the concentration index of explanatory variable; $\mathrm{C}$ stands for the concentration index of independent variable; Ref. indicates the reference group.

observed that NRCMS cannot promote inpatient service utilization for the older people. As mentioned above, NRCMS has a higher reimbursement rate for inpatient service than outpatient service, which significantly stimulated the demand of inpatient service for the older people. This finding also indicates that NRCMS has achieved one of the policy objectives. Furthermore, the regression result also indicates that need factors, such as being unhealthy and having chronic diseases, can lead to more inpatient expenses.

It was also found that NRCMS only played a limited role in reducing pro-rich inequality in inpatient service utilization among the older people in China. The reason lies in the fact that the reimbursement level of NRCMS is relatively lower. ${ }^{42}$ In addition, it is worth noting that need factors, including self-assessed health and chronic disease, played major roles in increasing pro-rich inequality in inpatient service utilization.

This study has several important policy implications. Firstly, it is necessary for the government to appropriately adjust the reimbursement policy of NRCMS, such as increasing the subsidies for the lower-income older inpatients to enhance financial protection, while reducing extra benefits for the higher-income older inpatients. Secondly, the government also needs to improve social security policy and reduce the unequal distribution of income. Thirdly, considering the fact that more than $7 \%$ of the respondents in this study were not covered by health insurance, there is a great need for the government to further expand the coverage of NRCMS. Last but not least, lower-income older adults should pay more attention to taking part in physical exercise and periodic physical examination, developing a healthy lifestyle, and strengthening the prevention of chronic diseases.

Considering that inpatient service can objectively reflect the health-care utilization and the rural older adults face significant barriers to health care, it is important to analyze the effect of NRCMS on socioeconomic inequality in inpatient service utilization among them. To the best of 
our knowledge, this is the first study to focus on the effect of NRCMS on socioeconomic inequality in inpatient service utilization among the Chinese older adults using the CFPS data. However, it must be acknowledged that this study has several limitations. Firstly, we cannot attain causal relationship due to the cross-sectional design. Secondly, self-assessed health used in this study suffered from the respondents' health consciousness level. ${ }^{15}$ Some respondents may overate or underrate their actual health status due to the different health consciousness levels, which may lead to overestimation or underestimation of their health status. Thirdly, given the fact that the data used in this study were self-reported, recall bias may exist in this study.

\section{Conclusions}

In conclusion, this study demonstrates that there was a prorich inequality in inpatient service utilization among the elderly in China. Furthermore, NRCMS was significantly associated with higher inpatient expense. Moreover, NRCMS only played a limited role in reducing pro-rich inequality in inpatient service utilization. It is suggested that some policy strategies, such as increasing the subsidies for the lower-income older adults covered by NRCMS, reducing the unequal distribution of income, and expanding the coverage of NRCMS, are required to alleviate inequitable distribution of inpatient service utilization.

\section{Abbreviations}

NRCMS, New Rural Cooperative Medical Scheme; CFPS, China Family Panel Studies; VIF, Variance Inflation Factor.

\section{Ethical Statement}

This study did not require an ethics committee approval regarding compliance with animal/human ethics guidelines.

\section{Funding}

This study was funded by National Social Science Foundation of China (15BJL003), Shanghai Philosophy and Social Science Planning Project (2014BJL002), National Natural Science Foundation of China (71704108), Research Foundation of Shanghai Municipal Development and Reform Commission of 2018, Scientific Research Foundation of Outstanding Young Teachers of Shanghai Jiao Tong University and SMC of 2016, and Urban Governance Foundation in Humanities and Social Sciences in Shanghai Jiao Tong University (16JCCS16).

\section{Disclosure}

The authors report no conflicts on interest in this work.

\section{References}

1. Hu H, Cao Q, Shi Z, et al. Social support and depressive symptom disparity between urban and rural older adults in China. $J$ Affect Disord. 2018;237:104-111. doi:10.1016/j.jad.2018.04.076

2. Hou J, Ke Y. Addressing the shortage of health professionals in rural china: issues and progress: comment on have health human resources become more equal between rural and urban areas after the new reform?' Int J Health Policy Manag. 2015;4(5):327-328. doi:10.15171/ijhpm.2015.57

3. Liu J, Li LW, Zhang Z, et al. Associations between physical health and depressive symptoms in Chinese older adults: do neighborhood resources matter? SSM Popul Health. 2016;2:531-535. doi:10.1016/j. ssmph.2016.07.001

4. Yang F, Lou VW. Childhood adversities, urbanisation and depressive symptoms among middle-aged and older adults: evidence from a national survey in China. Ageing Soc. 2016;36(5):1031-1051. doi:10.1017/S0144686X15000239

5. Yang F, Lou VW. Community restructuring and depressive symptoms of rural mature and elderly adults: a multilevel analysis based on a national dataset in China. Community Ment Health J. 2017;53 (1):34-38. doi:10.1007/s10597-016-0020-8

6. Zhou Z, Gao J, Xue Q, et al. Effects of Rural Mutual Health Care on outpatient service utilization in Chinese village medical institutions: evidence from panel data. Health Econ. 2009;18(S2):S129-S136. doi:10.1002/hec.1519

7. Meng Q, Mills A, Wang L, et al. What can we learn from China's health system reform? BMJ. 2019;365:12349. doi:10.1136/bmj. 12349

8. Chen Y, Jin GZ. Does health insurance coverage lead to better health and educational outcomes? Evidence from rural China. $J$ Health Econ. 2012;31(1):1-14. doi:10.1016/j.jhealeco.2011.11.001

9. Yan J, Ren Y, Zhou Z, et al. Research on the horizontal equity of inpatient benefits among NCMS enrollees in China: evidence from Shaanxi Province. BMC Health Serv Res. 2018;18(1):726. doi:10.1186/s12913-018-3534-7

10. Zeng Y, Li J, Yuan Z, et al. The effect of China's new cooperative medical scheme on health expenditures among the rural elderly. Int J Equity Health. 2019;18(1):27. doi:10.1186/s12939019-0933-2

11. Liu X, Sun X, Zhao Y, et al. Financial protection of rural health insurance for patients with hypertension and diabetes: repeated cross-sectional surveys in rural China. BMC Health Serv Res. 2016;16(1):481. doi:10.1186/s12913-016-1735-5

12. Cheng L, Liu H, Zhang Y, et al. The impact of health insurance on health outcomes and spending of the elderly: evidence from China's new cooperative medical scheme. Health Econ. 2015;24(6):672-691. doi:10.1002/hec.3053

13. Chen J, Dong H, Yu H, et al. Impact of new rural cooperative medical scheme on the equity of health services in rural China. BMC Health Serv Res. 2018;18(1):486. doi:10.1186/s12913-018-3288-2

14. Feng J, Liu F. The effect of new rural cooperative medical scheme on inequalities in health care utilization: evidence from 2004 and 2006 survey. Chin J Health Policy. 2012;5(3):45-51.

15. Zhou Z, Gao J, Fox A, et al. Measuring the equity of inpatient utilization in Chinese rural areas. BMC Health Serv Res. 2011;11 (1):201. doi:10.1186/1472-6963-11-201

16. Zhou Z, Zhu L, Zhou Z, et al. The effects of China's urban basic medical insurance schemes on the equity of health service utilisation: evidence from Shaanxi Province. Int J Equity Health. 2014;13(1):23. doi:10.1186/1475-9276-13-23 
17. Shao S, Wang M, Jin G, et al. Analysis of health service utilization of migrants in Beijing using Anderson health service utilization model. BMC Health Serv Res. 2018;18(1):462. doi:10.1186/s12913-0183271-y

18. Fu X, Sun N, Xu F, et al. Influencing factors of inequity in health services utilization among the elderly in China. Int $J$ Equity Health. 2018;17(1):144. doi:10.1186/s12939-018-0861-6

19. Li YN, Nong DX, Wei B, et al. The impact of predisposing, enabling, and need factors in utilization of health services among rural residents in Guangxi, China. BMC Health Serv Res. 2016;16(1):592. doi:10.1186/s12913-016-1825-4

20. Anderson JG. Health services utilization: framework and review. Health Serv Res. 1973;8(3):184-199.

21. Andersen RM. Revisiting the behavioral model and access to medical care: does it matter? J Health Soc Behav. 1995;36(1):1-10. doi: $10.2307 / 2137284$

22. Tesfaye G, Chojenta C, Smith R, et al. Application of the Andersen-Newman model of health care utilization to understand antenatal care use in Kersa District, Eastern Ethiopia. PLoS One. 2018;13(12):e0208729. doi:10.1371/journal.pone.0208729

23. Lai S, Shen C, Yang X, et al. Socioeconomic inequalities in the prevalence of chronic diseases and preventive care among adults aged 45 and older in Shaanxi Province, China. BMC Public Health. 2019;19(1):1460. doi:10.1186/s12889-019-7835-5

24. Yiengprugsawan V, Carmichael GA, Lim LLY, et al. Has universal health insurance reduced socioeconomic inequalities in urban and rural health service use in Thailand? Health Place. 2010;16 (5):1030-1037. doi:10.1016/j.healthplace.2010.06.010

25. Su M, Zhou Z, Si Y, et al. Comparing the effects of China's three basic health insurance schemes on the equity of health-related quality of life: using the method of coarsened exact matching. Health Qual Life Outcomes. 2018;16(1):41. doi:10.1186/s12955-018-0868-0

26. Lai S, Shen C, Xu Y, et al. The distribution of benefits under China's new rural cooperative medical system: evidence from western rural China. Int J Equity Health. 2018;17(1):137. doi:10.1186/s12939-0180852-7

27. Wagstaff A, Doorslaer E, Watanabe N. On decomposing the causes of health sector inequalities with an application to malnutrition inequalities in Vietnam. J Econom. 2003;112(1):207-223. doi:10.1016/ S0304-4076(02)00161-6

28. Peng $X$, Wang T. Does health insurance relive health inequality among children. China Ind Econ. 2017;34(12):59-77.

29. Wang Y, Wang J, Maitland E, et al. Growing old before growing rich: inequality in health service utilization among the mid-aged and elderly in Gansu and Zhejiang Provinces, China. BMC Health Serv Res. 2012;12(1):302. doi:10.1186/1472-6963-12-302
30. O’Donnell O, Van Doorslaer E, Wagstaff A, et al. Analyzing Health Equity Using Household Survey Data: A Guide to Techniques and Their Implementation. World Bank Institute Learning Resources Series 202-210. Washington DC USA: World Bank Publications; 2007.

31. Wagstaff A, Paci P, Van Doorslaer E. On the measurement of inequalities in health. Soc Sci Med. 1991;33(5):545-557. doi:10.1016/02779536(91)90212-U

32. Pan B, Towne SD, Chen Y, et al. The inequity of inpatient services in rural areas and the New-Type Rural Cooperative Medical System (NRCMS) in China: repeated cross sectional analysis. Health Policy Plan. 2017;32(5):634-646. doi:10.1093/heapol/czw175

33. Wagstaff A. Measuring and testing for inequality in delivery of health care. J Hum Resour. 2000;35(4):716-733. doi:10.2307/146369

34. Chen R, Li N, Liu X. Study on the equity of medical services utilization for elderly enrolled in different basic social medical insurance systems in an underdeveloped city of Southwest China. Int J Equity Health. 2018;17(1):54. doi:10.1186/s12939-018-0765-5

35. Wang Z, Chen Y, Pan T, et al. The comparison of healthcare utilization inequity between URRBMI and NCMS in rural China. Int J Equity Health. 2019;18(1):90. doi:10.1186/s12939-019-0987-1

36. Yu B, Meng Q, Collins C, et al. How does the new cooperative medical scheme influence health service utilization? A study in two provinces in rural China. BMC Health Serv Res. 2010;10(1):116. doi:10.1186/1472-6963-10-116

37. Zhang L, Tong X. Utilization of inpatient service and their influencing factors among the elderly in rural China: an empirical analysis based on the data of CHARLS. Nanjing J Soc Sci. 2014;4:67-74.

38. Liu X, Tang S, Yu B, et al. Can rural health insurance improve equity in health care utilization? A comparison between China and Vietnam. Int $J$ Equity Health. 2012;11(1):10. doi:10.1186/1475-9276-11-10

39. Wagstaff A, Lindelow M, Gao J, et al. Extending health insurance to the rural population: an impact evaluation of China's new cooperative medical scheme. J Health Econ. 2009;28(1):1-19. doi:10.1016/j. jhealeco.2008.10.007

40. Wagstaff A, Yip W, Lindelow M, et al. China's health system and its reform: a review of recent studies. Health Econ. 2009;18(S2):S7S23. doi:10.1002/hec. 1518

41. Zhang D, Xu Z, Chen P. Does“ basic health protection for all' improve farmers' health? Reassessing the effect of CNCMS on medical service utilization, health and income of inpatients. Chin J Socio. 2019;39(2):58-84.

42. Yan J, Yan Y, Hao N, et al. Empirical study on the relief effect of catastrophic health expenditure under three basic medical schemes. Chin Health Econ. 2012;31(1):26-28.
Risk Management and Healthcare Policy

\section{Publish your work in this journal}

Risk Management and Healthcare Policy is an international, peerreviewed, open access journal focusing on all aspects of public health, policy, and preventative measures to promote good health and improve morbidity and mortality in the population. The journal welcomes submitted papers covering original research, basic science, clinical \& epidemiological studies, reviews and evaluations, guidelines, expert opinion and commentary, case reports and extended reports. The manuscript management system is completely online and includes a very quick and fair peer-review system, which is all easy to use. Visit http://www.dovepress.com/testimonials.php to read real quotes from published authors. 